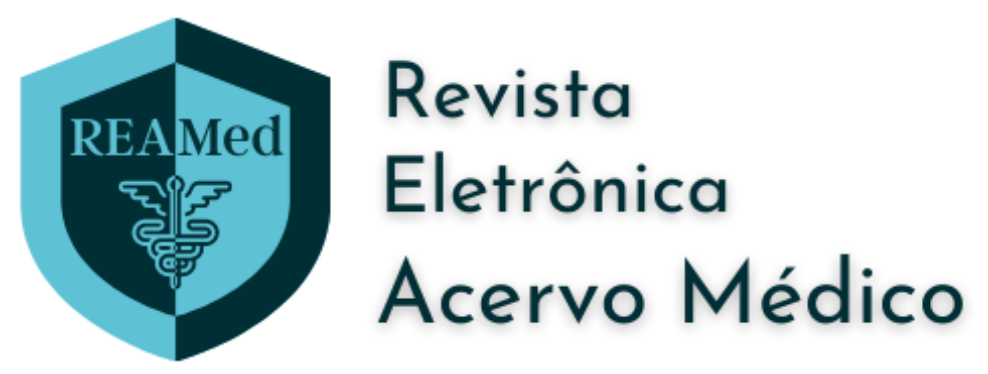

\title{
Tratamento dietético de pacientes com suspeita de intolerância a histamina: um relato de experiência
}

\author{
Dietary treatment of patients suspected of histamine intolerance: an experience report \\ Tratamiento dietético de pacientes con sospecha de intolerancia a la histamina: un \\ informe de experiencia
}

Keilla Lima Sirqueira ${ }^{1 *}$, Kelielson Cardoso de Macêdo Cruz².

\section{RESUMO}

Objetivo: Relatar a associação da dieta ao tratamento conservador medicamentoso, descrevendo a resposta clínica ao tratamento proposto em pacientes com suspeita de Intolerância à Histamina $(\mathrm{H})$. Relato de experiência: Trata-se de um relato do acompanhamento de pacientes com suspeita de $\mathrm{H}$ em uma Clínica de Alergia na região Centro-Oeste do Brasil. Os pacientes foram avaliados por 3 meses, a partir da primeira consulta médica e nutricional, e acompanhados durante a dieta restritiva em histamina, sendo subdividida em etapas e com última avaliação focada na evolução dos sintomas. Considerações finais: Ao decorrer do período de avaliação dos pacientes, a dieta restritiva de histamina teve uma função importante na melhora clínica dos pacientes com suspeita de intolerância a histamina, com diminuição dos sintomas e melhoria da qualidade de vida. Apesar de ser uma dieta com vários paramentos, sendo bem orientada e realizado por profissional capacitado, se torna uma medida acessível a ser adotada pelo paciente.

Palavras-chave: Histamina, Dieta, Intolerância alimentar.

\begin{abstract}
Objective: To report the association of diet with conservative drug response treatment, describing the clinical features of the proposed treatment in patients with suspected Histamine Intolerance (HI). Experience report: This is a follow-up report of patients with suspected $\mathrm{HI}$ in an Allergy Clinic in the Midwest region of Brazil. Patients were treated for 3 months, starting from the first medical and nutritional consultation, and followed up during the histamine-restricted diet, which was subdivided into stages and with the final assessment focused on the evolution of symptoms. Final considerations: During the period of evaluation of patients, the histamine-restricted diet played an important role in the clinical improvement of patients with suspected histamine intolerance, with a reduction in symptoms and improvement in quality of life. Despite being a diet with several vestments, being well oriented and carried out by a trained professional, it becomes an accessible measure to be adopted by the patient.
\end{abstract}

Key words: Histamine, Diet, Food intolerance.

\footnotetext{
1 Universidade de Brasília (UnB), Brasília - DF. *E-mail: keilla.limas@hotmail.com

${ }^{2}$ Centro Universitário do Pará (CESUPA), Belém - PA.
}

SUBMETIDO EM: 11/2021

PUBLICADO EM: 12/2021 


\section{RESUMEN}

Objetivo: Reportar la asociación de la dieta con el tratamiento conservador de respuesta farmacológica, describiendo las características clínicas del tratamiento propuesto en pacientes con sospecha de intolerancia a la histamina $(\mathrm{IH})$. Informe de experiencia: Este es un informe de seguimiento de pacientes con sospecha de $\mathrm{HI}$ en una Clínica de Alergia en la región del Medio Oeste de Brasil. Los pacientes fueron tratados durante 3 meses, a partir de la primera consulta médica y nutricional, y seguidos durante la dieta restringida en histamina, la cual se subdividió en etapas y la evaluación final se centró en la evolución de los síntomas.

Consideraciones finales: Durante el período de evaluación de los pacientes, la dieta con restricción de histamina jugó un papel importante en la mejoría clínica de los pacientes con sospecha de intolerancia a la histamina, con una reducción de los síntomas y una mejoría de la calidad de vida. A pesar de ser una dieta con varias vestimentas, bien orientada y llevada a cabo por un profesional capacitado, se convierte en una medida accesible para ser adoptada por el paciente.

Palabras clave: Histamina, Dieta, Intolerancia alimentaria.

\section{INTRODUÇÃO}

Na década de 40 a histamina foi descrita pela primeira vez como elemento desencadeador de reações tóxicas a partir do consumo de peixe (atum) transportado em condições inadequadas, e desde então vem sendo estudada e associada ao consumo de diversos alimentos. Em 2011 um relatório científico foi emitido sobre os níveis de aminas biogênicas em alimentos de circulação na União Europeia. Neste grupo de alimentos, a histamina se destacava como a amina de maior potencial tóxico, podendo representar risco à saúde, sendo um ponto de interesse em segurança alimentar, conforme dados da Autoridade Europeia para Segurança de Alimentos (EFSA) (COMAS-BASTÉ O, et al., 2020).

A histamina é uma amina biogênica formada a partir do aminoácido histidina, com várias funções, podendo representar riscos à saúde a depender da sua concentração e do sistema de degradação da mesma. (COMAS-BASTÉ O, et al., 2020; REESE I, et al., 2021). O ef eito fisiológico vai depender do receptor ao qual a histamina se ligou, podendo gerar ef eitos vasodilatadores, cardíacos, neurais, gástricos, secretórios e de contração muscular (SHULPEKOVA YO, et al., 2021; REESE I, et al., 2017).

Com esses efeitos, pode se deflagrar uma condição chamada de Intolerância a Histamina (IH) que representa o conjunto de reações adversas relacionadas à histamina ingerida ou exógena (HRUBISKO M, et al., 2021). Este conjunto de eventos está relacionado a uma alteração na metabolização da histamina por enzimas Diamina Oxidase (DAO) e Histamina-N-Metiltransferase (HNMT). Dependendo da localização, a histamina é desaminada pela ação da DAO, em meio extracelular, ou metilada pela ação da HNMT, em meio intracelular (REESE I, et al., 2021; HRUBISKO M, et al., 2021; SCHNEDL WJ, et al., 2021; TUCK CJ, et al., 2019; KOVACOVA-HANUSKOVA E, et al., 2015; KOHN JB, 2014).

Existem receptores específicos para histamina espalhados por vários órgãos, fator que justifica a diversidade dos sintomas de $\mathrm{H}$. Os sintomas envolvem alterações do Trato Gastrointestinal (TGI), como distensão e dor abdominal, diarreia, náuseas e/ou vômito, constipação; do sistema respiratório e cardiovascular, como palpitação e taquicardia; além de dor de cabeça, erupção cutânea e/ou prurido, rubor, rinorreia (MANZOTTI G, et al., 2016; REESE I, et al., 2021; HRUBISKO M, et al., 2021).

Os níveis de histamina em cada alimento dependem de vários fatores, entre eles o processo de armazenamento, processamento, grau de maturação (REESE I, et al., 2021) e até a presença de microorganismos com potencial de alterar o teor de histamina (HRUBISKO M, et al., 2021). Dessa forma, foi observado relação de causa e consequência de sintomas quanto ao consumo de frutas cítricas, morango, proteína animal, especialmente os peixes, ingestão de bebidas alcoólicas, especialmente vinho e cerveja, consumo de queijo, chocolates, conservantes e pimentas, entre outros (MUŠıČ E, et al., 2013).

Para o diagnóstico foi sugerido uma sequência de critérios: Estágio 1) 2 ou mais sintomas característicos de intolerância à histamina, história clínica compatível e exclusão da possibilidade de reações alérgicas 
mediadas porlgE e mastocitose sistêmica, e de doenças do TGI; Estágio 2) Registro alimentar 2 a 8 semanas para mapeamento dos possíveis a gatilhos alimentares; Estágio 3) Diagnóstico baseado na atividade sérica de DAO (DAO < $10 \mathrm{U} / \mathrm{ml}$ ) ou biópsia intestinal, teste de desafio oral de histamina ou teste cutâneo com histamina (com duração superior à 50 minutos), investigação genética para polimorfismos de DAO, avaliação de metabólitos da DAO em fezes e urina (SHULPEKOVA YO, et al., 2021).

Foi realizado, neste trabalho, relato de experiência sobre a aplicação de dieta restritiva em histamina em uma clínica de alergia na região Centro-Oeste do Brasil. O público era de demanda espontânea, com suspeita de intolerância à histamina que se submeteram à dieta restritiva além de medicação anti-histamínica. 0 objetivo principal foi relatar, a partir da prática clínica vivida, a associação da dieta ao tratamento conservador medicamentoso, descrevendo a resposta ao tratamento proposto focado na melhoria dos sintomas.

\section{RELATO DE EXPERIÊNCIA}

Em atendimento clínico para tratamento de queixas alérgicas, foi observado que, recorrentemente, sintomas do TGI estavam associados àqueles cutâneos. Este fato despertou o interesse em pesquisar mais a fundo a relação entre queixas alérgicas e consumo alimentar. Nesse contexto, e mediante revisão científica, os autores buscaram estabelecer um protocolo de tratamento multiprofissional, considerando as queixas comuns e a ingestão alimentar.

Inicialmente foram elencados os principais sintomas característicos de $\mathrm{H}$, além de doenças do TGl que podem estar associadas. A investigação diagnóstica também considera a presença de urticária, dermatite atópica, e intolerância à lactose, glúten, alergias alimentares, além de doenças crônicas prévias.

Durante a consulta médica buscou-se estabelecer os critérios para a suspeita de IH levando em consideração a história clínica detalhada, a presença de pelo menos 2 sintomas característicos de $\mathbb{H}$ e a exclusão de outros diagnósticos a partir de testes alérgicos iniciais, exames laboratoriais específicos, sendo posteriormente o paciente é encaminhado para a nutricionista.

A anamnese nutricional, leva em consideração o histórico familiar, cirúrgico e de patolog ias prévias, além do uso de medicamentos, ciclo menstrual e uso de anticoncepcionais. Sequencialmente, interroga-se também quanto ao seu estilo de vida, tabagismo, etilismo, atividade física, entre outros.

Por sua vez, a investigação alimentar é conduzida de modo a identificar intolerâncias e alergias prévias, preferências alimentares, volume de ingestão hídrica, tempo de mastigação, além de outros parâmetros associados aos hábitos alimentares. Neste momento, é aplicado um recordatório de 24 horas, que busca identificar a rotina de vida e alimentar. Além disso, é feita a análise dos exames bioquímicos e a descrição dos sintomas, e sua eventual relação com um alimento ou grupo alimentar.

A terapia conjuntamente estabelecida é baseada na restrição alimentar, subdividida em 3 etapas. Além de orientações sobre a $\mathrm{IH}$ e disponibilidade de acompanhamento, e suporte de dúvidas via canais virtuais. Dessa forma, é feita a instrução inicial, que considera a restrição de alimentos que possuem elevados teores de histamina, ou são potencialmente histamínicos. Já a segunda etapa, que pode durar de 2 a 6 semanas, consiste na reintrodução gradual dos alimentos, associada ao registro pelo paciente de eventuais reações adversas. Porfim, a terceira etapa consiste na manutenção de uma dieta variada, com exclusão dos alimentos registrados pelo paciente que causaram sintomas, evoluindo para uma dieta individualizada. Esta é denominada etapa de manutenção.

Mediante aplicação deste protocolo, foi observado melhora do quadro clínico, associada a redução dos principais sintomas relatados como queixa ao início do tratamento. Na segunda fase do tratamento nutricional, foi observado a queixa de recidiva dos sintomas, sendo feita a orientação para a suspensão do consumo do alimento imediatamente.

\section{DISCUSSÃo}

Segundo Enko D, et al. (2016), entre os sintomas com maior prevalência estão distensão abdominal e flatulência, diarreia, dor e desconforto abdominal, náuseas e vômitos, arroto e azia, e constipação intestinal 
em menor ocorrência. Também existem referências a presença de cefaleia e enxaqueca como sintomas (SCHNEDL WJ e ENKO D, 2021; COMAS-BASTÉ O, et al., 2020). O que corrobora para o enquadramento dos sintomas presentes nos pacientes avaliados, os quais apresentavam dor e desconforto abdominal, distensão abdominal, alterações cutâneas, cefaleia e no sistema respiratório, como rinorreia e rinite.

Estudos mostram que $77,7 \%$ dos pacientes apresentaram intolerância à histamina, má absorção de frutose ou de lactose, individualmente ou combinadas entre si, sendo que as mais prevalentes a intolerância à histamina e a má absorção de lactose isoladamente. Mais de $1 / 3$ dos indivíduos com má absorção de lactose apresentam intolerância à histamina, este fator pode estar associado à similaridade dos sintomas de ambas as condições, reforçando a dificuldade para o diagnóstico e tratamento correto dos pacientes pelos médicos e nutricionista. Além disso, o dano na mucosa intestinal causado por condições clínicas como diarreia, Síndrome do Intestino Irritável (SII), uso de medicamentos entre outros, pode causar a redução da atividade da DAO e da secreção de lactose, sendo uma possível explicação para sobreposição entre má absorção de lactose e intolerância à histamina (ENKO D, et al., 2016).

Quando se volta o foco para os alimentos, de modo geral, eles podem conter aminas biogênicas, como a tiramina, putrescina e cadaverina, também formadas a partir da desaminação enzimática, além da histamina. A presença destes componentes deriva de diversos fatores, como a disponibilidade de aminoácidos precursores, condições ambientais favoráveis à descarboxilase bacteriana (COMAS-BASTÉ O, et al., 2020; SÁNCHEZ-PÉREZ S, et al., 2018).

Sabe-se que quanto mais fresco e não contaminado o alimento, menor a probabilidade de apresentar níveis elevados de aminas biogênicas. $O$ tratamento térmico não tem a capacidade de reduzir os níveis de histaminas já presentes nos alimentos, apesar disso, cozinhar em imersão em água pode estimular a transferência da histamina do alimento para a água de cocção, que se descartada elimina a histamina que foi transferia a ela (HRUBISKO M, et al., 2021).

Apesar disso, dentro do corpo literário não há um consenso que torne clara a relação entre a presença de aminas sozinhas ou combinadas e a degradação de histamina pela enzima DAO, mesmo sendo habitualmente notado nos estudos os resultados benéficos de dietas restritivas (SÁNCHEZ-PÉREZ S, et al., 2021). Sendo assim, a proposta de dieta restritiva como tratamento em casos de suspeita de $I H$, consiste em três momentos (REESE I, et al., 2021; HRUBISKO M, et al., 2021; COMAS-BASTÉ O, et al., 2020).

A primeira etapa, com duração de 15 dias, indica-se a restrição completa de alimentos classificados como com alto teor de histamina, e com potencial histamínico (LACKNER S, et al., 2019). A seleção dos alimentos a serem restritos, foi baseada nos hábitos e cultura alimentar, considerando que a literatura, traz de modo praticamente unânime a restrição de alimentos fermentados, como salsichas e linguiças fermentadas a seco, queijos curados, chucrute, derivados fermentados da soja, vinhos e cerveja. Das fontes de proteína animal, a indicação de restrição predomina quanto aos pescados, não sendo indicada a restrição de carnes bovina, suína e aves, desde que tenham sido mantidas em boas condições de higiene (SÁNCHEZ-PÉREZ S, et al., 2021).

Quanto aos vegetais, o que tem a indicação de restrição do consumo por apresentarem níveis mais altos de histamina são o tomate, berinjela e espinafre, principalmente 15 dias ou mais após sua colheita, mesmo que armazenados sob refrigeração. Apesar de serem comumente restringidos nas dietas anti-histamínicas, alguns alimentos não possuem quantidades notavelmente importantes de histamina, sendo eles, frutas cítricas, banana, soja, abóboras e nozes (SÁNCHEZ-PÉREZ S, et al., 2021).

Na segunda etapa do tratamento, orienta-se que sejam incluídos um alimento, a cada três dias, iniciando com aqueles com menor teor de histamina, e sequencialmente aqueles com maior concentração histamínica. Nesta fase, é importante que o paciente faça um registro de eventuais reações adversas, considerando alterações do TGI, sintomas alérgicos, cefaleia sem causa específica e distúrbios cardiovasculares, com a suspensão imediata do alimento que desencadeou o sintoma. Dessa forma, é possível realizar o mapeamento individualizado os principais alimentos que causam reações adversos em cada indivíduo (REESE I, et al., 2021; HRUBISKO M, et al., 2021; COMAS-BASTÉ O, et al., 2020; REESE I, 2018). 
Em relação à terceira e última etapa do tratamento, os pacientes devem ser orientados à uma dieta balanceada, com restrição apenas dos alimentos que, individualmente foi observado como desencadeador de sintomas (REESE I, et al., 2021; HRUBISKO M, et al., 2021; COMAS-BASTÉ O, et al., 2020). A partir do que foi aplicado, foi observado que a primeira e segunda etapa são determinantes para que a fase final seja segura.

Apesar dos bons resultados mediante à restrição alimentar, e conforme previamente descrito na literatura, uma das principais queixas relacionadas à adesão da dieta é a falta de informação comercial relacionada a presença e quantidade desse elemento nos alimentos. Para auxiliar os pacientes com Intolerância à histamina, seria essencial que houvesse nos produtos a informação de que contém ou não histamina no rótulo ou na lista de ingredientes de forma clara, e a sua quantidade na porção do alimento (MARTIN ISM, et al., 2016).

A partir da história clínica e bioquímica dos pacientes, em casos isolad os foi realizado também ao longo do tratamento a suplementação nutricional. A desnutrição pode aumentar a sensibilidade à histamina. Isso porque nessa condição há menos disponibilidade de cofatores enzimáticos, principalmente as vitaminas $\mathrm{C}$, cobre e vitamina B6, influenciando assim no processo de intolerância à histamina (HRUBISKO M, et al., 2021).

Em casos de queixas importantes de alterações do trânsito intestinal, foram utilizadas fórmulas manipuladas individualizadas de probióticos como tratamento associado. Há evidências, apesar de frágeis, de que o uso de Lactiplantibacullus plantarum podem funcionar como degradadores de histamina, mas esse fato ainda não foi comprovado em humanos e apenas em amostras experimentais. Também, como o mesmo objetivo podem ser utilizados os probióticos dafamília Bifidobacterium (HRUBISKO M, et al., 2021; KOHN JB, 2014).

Por fim, observou-se que a redução dos sintomas está claramente associada à adesão do paciente à dieta restritiva, de forma que aqueles que apresentaram maior dificuldade em restringir os alimentos na primeira etapa, mantiveram queixas, principalmente do TGI por maior período de tempo. Ao final do tratamento, foi relatado maior autonomia na escolha dos alimentos, uma vez que os pacientes já tinham adquirido consciência a respeito de quais alimentos Ihes causavam reações alérgicas, sendo possível manter uma dieta variada e não agressiva.

\section{REFERÊNCIAS}

1. COMAS-BASTÉ O, et al. Histamine Intolerance: The Current State of the Art. Biomolecules, 2020;10(8):1181.

2. ENKO D, et al. Concomitant Prevalence of Low Serum Diamine Oxidase Activity and Carbohydrate Malabsorption. Canadian journal of gastroenterology \& hepatology, 2016;2016:4893501.

3. HRUBISKO M, et al. Histamine Intolerance-The More We Know the Less We Know. A Review. Nutrients, 2021; 13(7): 2228.

4. KOHN JB. Is There a Diet for Histam ine Intolerance?. Journal of the Academy of Nutrition and Dietetics, 2014; 114(11): 1860.

5. KOVACOVA-HANUSKOVA E, et al. Histamine, histamine intoxication and intolerance. Allergologia et immunopathologia, 2015;43(5):498-506.

6. LACKNER S, et al. Histamine-reduced diet and increase of serum diamine oxidase correlating to diet compliance in histamine intolerance. European journal of clinical nutrition, 2019;73(1):102-104.

7. MANZOTTI G, et al. Serum diamine oxidase activity in patients with histamine intolerance. International journal of immunopathology and pharmacology, 2016;29(1):105-111.

8. MARTIN ISM, et al. Histamine intolerance and dietary management: A complete review. Allergologia et immunopathologia, 2016;44(5):475-483.

9. MUŠıČ E, et al. Serum diamine oxidase activity as a diagnostic test for histamine intolerance. Wien Klin Wochenschr, 2013;125(9-10):239-243.

10. REESE I, et al. German guideline for the management of adverse reactions to ingested histamine: Guideline of the German Society for Allergology and Clinical Im munology (DGAKI), the German Society for Pediatric Allergology and Environmental Medicine (GPA), the German Association of Allergologists (AeDA), and the Swiss Society for Allergology and Immunology (SGAI). Allergo journal international, 2017;26(2): 72-79. 
11. REESE I. Nutrition therapy for adverse reactions to histamine in food and beverages. Allergologie Select, 2018;2(1): 56-61.

12. REESE I, et al. Guideline on management of suspected adverse reactions to ingested histamine: Guideline of the German Society for Allergology and Clinical Immunology (DGAKI), the Society for Pediatric Allergology and Environmental Medicine (GPA), the Medical Association of German Allergologists (AeDA) as well as the Swiss Society for Allergology and Immunology (SGAI) and the Austrian Society for Allergology and Immunology (ÖGAI). Allergologie Select, 2021; 5: 305-314.

13. SÁNCHEZ-PÉREZ S, et al. Biogenic Amines in Plant-Origin Foods: Are They Frequently Underestimated in LowHistamine Diets?. Foods (Basel, Switzerland), 2018; 7(12): 205.

14. SÁNCHEZ-PÉREZ S, et al. Low-Histamine Diets: Is the Exclusion of Foods Justified by Their Histamine Content?. Nutrients, 2021;13(5): 1395.

15. SCHNEDL WJ, Enko D. Histamine Intolerance Originates in the Gut. Nutrients, 2021; 13(4): 1262.

16. SHULPEKOVA YO, et al. Food Intolerance: The Role of Histamine. Nutrients, $2021 ; 13(9): 3207$

17. TUCK CJ, et al. Food Intolerances. Nutrients, 2019; 11(7): 1684. 